\title{
Hacia un modelo de análisis del discurso más comunicacional. África en los digitales españoles
}

\author{
Luis Concepción SEPúlvedA \\ Universitat Ramon Llull \\ luisgilbertocs@blanquerna.url.edu \\ Alfons Medina CAMBRón \\ Universitat Ramon Llull \\ alfonsomc@blanquerna.url.edu
}

Recibido: 24 de julio de 2014

Aceptado: 5 de febrero de 2015

\section{Resumen}

En primer lugar, presentamos una herramienta metodológica que pone la comunicación en el centro del análisis del discurso. Inspirada en la Pragmática Formal de Habermas, el lenguaje trasciende el marco exclusivamente lingüístico para ser estudiado desde los prismas social, subjetivo y objetivo. En segundo lugar, comprobamos que su aplicación en un análisis de contenido sobre el tratamiento mediático de África en www.elpais.com y www.elmundo.es permite un acercamiento más cabal y dinámico al objeto de estudio. Al situar la noticia en un acto de comunicación entre periodistas y lectores, se redefine el papel del significado del texto para explorar el tipo de comunicación que se establece, sus repercusiones, la actitud y los intereses de los profesionales de la comunicación

Palabras clave: Análisis del discurso, Habermas, África, El País, El Mundo.

\section{Toward a communication model of discourse analysis. Africa in the Spanish digitals}

\begin{abstract}
Firstly, we present a model of discourse analysis that it puts communication in the center. Inspired by Habermas' Formal Pragmatics, language transcends the linguistic framework to be studied from the social, subjective and objective point of view. Secondly, we apply this methodology model on a content analysis of Africa's news in www.elmundo.es and www.elpais.com. We check what allows a more qualitative approach to its media treatment. By placing news in an act of communication between journalists and readers, it opens the possibility to track the attitude and the interests of journalist, and let infer what kind of communication is to be established and its implications.
\end{abstract}

Keywords: Discourse analysis, Habermas, Africa, El País, El Mundo.

\section{Referencia normalizada}

CONCEPCIÓN SEPÚLVEDA, Luis y MEDINA CAMBRÓN, Alfons (2015): "Hacia un modelo de análisis del discurso más comunicacional. África en los digitales españoles". Estudios sobre el Mensaje Periodístico. Vol. 21, Núm. 2 (julio-diciembre), págs.: 773-791. Madrid, Servicio de Publicaciones de la Universidad Complutense.

Sumario: 1. Introducción. 2. Fuentes y metodología. 3. Desarrollo. Ejemplificación del triple análisis. Estudio de caso de la imagen africana en El Mundo y El Pais; 3.1. El Mundo, camino a la asepsia; 3.1.1. La ciencia en El Mundo; 3.1.2. La salud en África, a debate; 3.2. El País olvida al lector; 3.2.1. La inmigración irregular; 3.2.2. La enfermedad y el hambre. 4. Conclusiones. 5. Referencias bibliográficas.

\section{Introducción}

En el área de la investigación en comunicación han predominado durante décadas las teorías que han tenido como tema central la influencia de los medios de comunicación sobre los públicos o las audiencias. Sin embargo el estudio de la influencia, desde una 
perspectiva totalizadora, tal y como era presentado en sus inicios, ha sido ampliamente corregido y matizado con la aportación de diferentes modelos teóricos. No obstante sigue teniendo una fuerte presencia teórica y también, evidentemente, mediática (Busquet y Medina, 2014). Las primeras investigaciones en comunicación, que tomaron como objeto de estudio la inmigración, por ejemplo, se centraron en la imagen y en los estereotipos de los inmigrantes en los medios de comunicación. Por tanto, el análisis de las relaciones que se daban entre la comunicación y la inmigración se circunscribía, preferentemente, al papel de los medios de comunicación de masas en la representación de los nuevos ciudadanos (Concepción y Medina, 2011). Así el mundo académico se preocupaba en aquel momento por un movimiento que crecía exponencialmente. En España el análisis de contenido de este tipo de noticias, que describían sobre todo la llegada de subsaharianos y marroquíes a las costas españolas, intentaba arrojar una luz más sosegada frente a la escalada informativa de signo negativo (Concepción et al., 2008; Concepción y Medina, 2011). Sin embargo el interés académico evoluciona y se abre poco a poco al estudio de la dieta mediática de la inmigración como una nueva audiencia y al impacto de las noticias de inmigración en la sociedad de acogida (Chavero et al., 2005; Igartua et al., 2005; Bernárdez, 2007; Altarriba et al., 2008; Ayuste et al., 2009; Canosa et al., 2009; Cogo et al., 2012). No obstante, en la actualidad la hegemonía continúa estando en manos del análisis de contenido de las noticias (Nerín y López, 1999; El-Madkouri, 2004, 2006; Taibi et al., 2006; Freixa, 2012, 2013; Sendín 2004, 2006; Castel y Sendín, 2009; Bañón Hernández 2006; 2007, 2010; Concepción et al., 2008).

Sin menospreciar las diferentes líneas de investigación abiertas, en este artículo queremos presentar un modelo metodológico que permita analizar con más complejidad el análisis de contenido, a partir de las noticias sobre África, en los medios de comunicación generalistas.

Desde mediados de los noventa, la inmigración en su conjunto comienza a crecer en España de manera espectacular. En aquellos años también se da una verdadera eclosión de noticias sobre las pateras. Sin duda era mucho más espectacular y "noticiable" una crónica sobre una penosa y aventurera travesía, que informar desde el aeropuerto de la llegada de subsaharianos en vuelos comerciales.

Esta sobreexposición mediática sin precedentes no se correspondía con la proporción de africanos en el total de inmigrantes. En cambio, la hegemonía de la imagen del africano en las noticias migratorias comienza a modelar el imaginario español sobre un fenómeno que estaba cambiando el país y la autoimagen de los ciudadanos (Bauböck, 2004). Desde entonces, se han ido produciendo representaciones más lesivas que las tradicionales hasta que la crisis económica ha relegado a la inmigración a un problema secundario en el barómetro del CIS (Centro de Investigaciones Sociológicas) ${ }^{1}$.

1 Según los datos del CIS, en septiembre de 2001 la inmigración era uno de los tres problemas principales para un $12,9 \%$ de la población española. En abril de 2005 era de un $29,5 \%$ y en septiembre de 2006 un 59,6\% de los españoles consideraba que la inmigración estaba entre los tres principales problemas del país. Durante los meses de verano de 2006 las portadas de los principales periódicos abrían con noticias relacionadas con la llegada de inmigrantes ("Zapatero afronta en Canarias un desembarco masivo de inmigrantes" titulaba $\mathrm{La}$ 
Este trabajo tiene dos objetivos: en primer lugar, presentar una herramienta compleja de análisis de las narraciones autobiográficas que no sea sólo sociológica o lingüística, sino también y sobre todo comunicacional. En segundo lugar, comprobar si su aplicación en un análisis de contenido sobre las noticias de África en los dos diarios digitales de referencia en España, www.elmundo.es y www.elpais.com, permite una aproximación distinta, más cualitativa, al tratamiento mediático de África y a la inmigración africana en España. A través de este análisis, también queremos conocer si existe algún tipo de diferencia entre diarios alejados ideológicamente y explorar sus imágenes dominantes.

\section{Fuentes y metodología}

Nuestro marco teórico tiene como punto de partida la ruptura con la razón centrada en el sujeto individual cognoscente. Este principio de subjetividad se larva durante mucho tiempo y en diferentes campos. Si bien es verdad que comienza con la filosofía (Husserl, 1991), no es menos cierto que da su salto a la política y a la ética con la Reforma y la Revolución Francesa (Habermas, 2008). Sin embargo, la puesta en práctica de este principio en la relación del ser humano con su mundo se acelera con la Revolución Industrial. En este período, la necesidad de objetivar la naturaleza para extraer sus recursos se vuelve más imperiosa con la escalada de las ingenierías. Heidegger lo define bien cuando asegura que sin darse cuenta se establece un nexo de dependencia con la naturaleza, que lo emplaza a explotarla cada vez con más fuerza (Heidegger, 1994: 9-32).

Estas facetas de lo que comúnmente se conoce como individualismo o principio de subjetividad cristalizan en la modernidad. La hegemonía de este paradigma en todas las áreas de la vida y la progresiva implantación del derecho privado, que protege ya formalmente la libertad subjetiva, terminan por dar legitimidad a la persecución racional de los propios intereses. Todos estos factores explican a grandes rasgos por qué la teoría del conocimiento parte de la representación de un individuo solitario que sale al encuentro de objetos que quiere conocer y manipular, por qué en el plano ontológico el sujeto se limita a enfrentarse al mundo del ente, y por qué la semántica se queda varada en el habla constatativa de hechos (Habermas, 2008: 322-338). La subjetividad da rienda suelta a la objetividad y el conocimiento de objetos se convierte en la única forma de relacionarse con el mundo y de comprender la razón.

Esta reducción de las posibilidades de la razón también abarca el lenguaje, que sólo puede desarrollar una función cognitiva. Ya sólo representa objetos y hechos, y se limita a emitir enunciados verdaderos (Habermas, 2008: 338).

Vanguardia el 20 de agosto de 2006). Con el inicio de la crisis la percepción de la inmigración como problema pasará a un segundo plano. En junio de 2013 tan solo el 2,8\% de la población considera que la inmigración es uno de los tres principales problemas del país y solo se produce un leve repunte con los sucesos de Melilla de febrero de 2014 (5,9\%). No obstante, las portadas continúan recogiendo una imagen del tema de la inmigración en que es relativamente sencillo que el resto de la población la perciba como un peligro o una amenaza (“30.000 subsaharianos preparan el salto a Europa por Ceuta y Melilla titulaba El País el 17 de febrero de 2014). 
Sin embargo, con la entrada en escena de la compleja noción de mundo de la vida o lebenswelt ${ }^{2}$ se abre el lenguaje a nuevas dimensiones para su análisis:

- Dimensión Social

- Dimensión Subjetiva

- Dimensión Objetiva

Si el mundo de la vida nace con Husserl para poner en cuestión los cimientos de las ciencias desde la arqueología social de los objetos que estudia, la intersubjetividad que abandera quiere inaugurar un nuevo comienzo para una filosofía que se estaba agotando en el sujeto y en la conciencia. Precisamente a partir de este concepto, el conjunto de conocimientos prerreflexivos de la vida en comunidad, Habermas arma las piezas de un relato teórico que va a permitir desarrollar una interesante metodología para el análisis del discurso. Así, ensambla los actos de habla de la filosofía del lenguaje anglosajona de Austin (1982) y Searle (2001), las funciones del lenguaje de Karl Bühler y, desde un punto de vista más epistemológico, la teoría de los tres mundos de Karl Popper (Habermas, 2008). Con el análisis habermasiano el lenguaje ya no se supedita a una función representativa o constatativa, ligada a un mundo de objetos. Ahora aparecen dos nuevas dimensiones que la complementan, el mundo subjetivo de la función expresiva y el mundo social que regula las relaciones humanas. El mundo de la vida está presente en estas tres dimensiones, en la base de procesos como la reproducción cultural, la integración social y la cooperación de la acción, pero también en la socialización del individuo. La ingeniería comunicativa del lenguaje, el lenguaje planteado en términos de comunicación, es la llave para recorrer las distintas esferas, conectadas entre sí por un sistema frágil de interdependencia. Efectivamente el potencial comunicativo del lenguaje es lo que lo hace posible.

Como decíamos, una metodología con una importante carga teórica tiene la intención de desviarse del camino trazado de antemano por los tradicionales análisis de contenido. Carga teórica porque la introducción del concepto "mundo de la vida" o lebenswelt en el apartado de la Pragmática Formal y en la interpretación habermasiana de los actos de habla ayuda a situar el lenguaje fuera de la concepción instrumental del neopositivismo y de la filosofía del sujeto. De esta manera la comunicación pasa a primer plano, con lo que el lenguaje trasciende el marco lingüístico para ser estudiado a través de otros prismas, desde el sociológico al de la estética del mundo subjetivo. $Y$ es que en la noticia se entrelazan el mundo individual, social y cultural de una manera apenas explorada hasta la fecha.

En el análisis se seleccionaron 40 noticias en total de las ediciones digitales de $E l$ Mundo y El País durante los meses de marzo y abril de 2012, a partir de la búsqueda de la palabra clave "África" en las respectivas hemerotecas virtuales. Estudiamos estos dos potentes diarios en línea porque es indudable que los modos de producción de contenidos, las representaciones mediáticas y los hábitos de consumo están teniendo lugar en el ciberespacio más que en ningún otro medio. Y si la red concentra hoy la mayor

2 La reelaboración del concepto husserliano de mundo de la vida, corregido y ampliado por el propio Habermas y puesto al servicio de una teoría de la comunicación. 
producción de contenidos y representaciones de lo africano será el espacio en el que sus efectos se dejarán sentir con más fuerza (Leung, 2008). De ahí que su análisis tenga una importancia capital para radiografiar cómo se habla de África desde España.

Al diseñar una herramienta de análisis viable hay que intentar superar bipolaridades recurrentes que a menudo aparecen en los estudios de contenido. Situar la metodología en un punto intermedio, fuera de los extremos, debería ser un imperativo categórico. De esta forma, la propuesta metodológica intenta romper con algunos tópicos del análisis del contenido:

- Una relación más libre con el texto:

La pragmática formal de Habermas permite entender la noticia más allá de ella misma. Funda las bases para una relación más libre con el texto, por encima de las interpretaciones excesivamente lingüísticas y por debajo de las demasiado sociológicas. Se huye así de dos extremos, entre los análisis que tratan el lenguaje como un sucedáneo de la realidad social que no expresa más que su sentido literal, y los que se olvidan de conectar el texto con la realidad social en la que se inscribe. Una buena instantánea de África debe colocar en un mismo nivel las condiciones contextuales (sociales, históricas, mediáticas) presentes en el texto y el rol que juega el lenguaje en la producción de prácticas y procesos sociales (Alonso y Callejo, 1999:67).

- Superar la concepción limitada del significado:

Tradicionalmente el análisis de contenido de las noticias se ha limitado a estudiar las intenciones del periodista a través del significado del texto. Sin embargo, la semántica debe colocarse en el plano interpersonal del producto mediático. Y es que el significado está "convencionalmente regulado", porque el oyente debe reconocerlo y comprenderlo (Muñoz, 2014: web). De ahí que el significado no sea atribuible únicamente al emisor o al texto, es más bien un producto inacabado que no depende sólo del periodista. La semántica, en definitiva, tiende puentes entre el emisor y el receptor y aunque este último no lo podemos invocar en el análisis, sí que podemos aproximarnos a él a través del texto.

- Trascender la función representativa del lenguaje:

Significa apartarnos de la vía marcada por la filosofía del sujeto, de un modelo de conocimiento basado únicamente en la vertiente cognitiva y en un mundo objetivo.

- Un análisis interpretativo:

El marco teórico de esta metodología permite romper con el plano descriptivo del análisis, que no suele estar preparado para arrojar interpretaciones más complejas.

- Combinar la perspectiva global y la local:

La mayoría de los análisis de contenido parten de una visión global del texto y resumen los grandes ejes narrativos de la representación mediática del objeto de estudio. Sin embargo, si las ideas más generales expresadas en el titular tienen la fuerza del primer impacto en el lector, los aspectos locales del texto contienen una carga simbólica, subestimada en numerosos estudios y que es tan 
importante como el análisis global de la noticia. Por su sutilidad, sus contenidos latentes interactúan y negocian sus significados con el receptor en superioridad de condiciones, porque operan a escala "subliminal".

El modelo de análisis que proponemos va a lograr interpretaciones de mayor recorrido del producto informativo, tanto hacia adentro, en dirección a la semántica, como hacia afuera, rumbo a los vínculos que entrelazan el texto y la realidad extratextual. Contiene tres apartados: análisis periodístico, análisis semántico y análisis pragmático formal.

Desde un análisis periodístico se evaluarán la calidad de la información y el tipo de cobertura que ha realizado el periodista. Los criterios se inspiran en los de Blanco (2008). Se divide en dos apartados. El referente al contenido y a la situación de la noticia:

- Tema

- Sección en que se inscribe

- Tipo de relato

- Información completa/ incompleta

- Fuentes

- Tipos de fuentes

- Género periodístico.

Y el análisis centrado en la manera de abordar la información:

- Superficialidad o profundización de los acontecimientos

- Valoración de los aspectos positivos o negativos

- Transmisión de valores

- Presencia de un discurso cultural y moral que favorece el sentido crítico y el diálogo.

El segundo tipo de análisis se basa en la semántica textual. Según el modelo de Jensen y Jankowski (1993), la semántica textual estudia el significado de las noticias desde dos niveles: la semántica global y la local. En la primera, se pone el acento en la semántica más general, en las ideas más abstractas de la noticia, frecuentemente alojadas en el titular. Éste ocupa la posición más jerárquica dentro de la estructura temática del texto. Por otra parte, la semántica local queda desglosada en epígrafes importantes que guían un análisis más detallado de la noticia. De esta manera se tienen en cuenta elementos relevantes como la coherencia local (o los nexos de unión entre las oraciones), el estilo y la retórica.

El tercer tipo de análisis es el de la Pragmática Formal, que no suele estar presente en la mayoría de estudios sobre las representaciones mediáticas. Permite remontar el texto de la noticia para identificar la clase de comunicación que se establece entre el periodista y el lector. En él se recuperan elementos pragmáticos del habla tradicionalmente olvidados por lingüistas, filósofos y comunicólogos, como el análisis del uso y las intenciones del hablante (Muñoz, 2014). Nuestro análisis de las noticias se ha guiado por la siguiente clasificación, que muestra los tipos de habla más frecuentes (Habermas, 1999a; 1999b): 
- Forma de habla constatativa:

- Es un modo de comunicación cognitivo, que remite al conocimiento.

- El emisor se refiere a una realidad externa y objetiva.

- Se expresan convicciones.

- El emisor tiene una actitud objetivante.

- La función comunicativa del lenguaje es la presentación de un estado de cosas.

- La primera función social del lenguaje es generar entendimiento; la segunda, activar la transmisión del saber cultural.

- La pretensión de validez del texto o del habla es la verdad.

- La autoridad del texto viene dada por la objetividad de la experiencia del periodista o hablante.

- Forma de habla regulativa:

- Es un modo de comunicación interactivo. Se da una estrecha relación entre acción y lenguaje.

- El emisor se refiere a algo en el mundo social para establecer una relación interpersonal que sea reconocida como legítima

- El periodista desarrolla una actitud de conformidad con las normas sociales.

- Es la más social y vinculada a la acción de estas formas del lenguaje. La función comunicativa del lenguaje es la apelativa. En primera instancia, coordina la acción; y en segunda, desencadena conductas de conformidad con las normas y tradiciones, y contribuye a la integración social del individuo.

- El hablante plantea una pretensión de validez normativa, basada en los usos y costumbres de una determinada comunidad.

- La autoridad del texto es la verdad moral pero en la forma de validez normativa. Es fruto de un acuerdo idealizado y es el uso del lenguaje más fuertemente marcado por la intersubjetividad habermasiana.

- Es el uso del lenguaje que despierta una mayor motivación para que el lector acepte la oferta del acto de habla.

- Forma de habla expresiva:

- Es un modo de comunicación expresivo.

- El hablante se refiere a algo perteneciente a su mundo subjetivo, en el sentido de desvelar una vivencia personal.

- La función del lenguaje es expresiva, ya que el hablante se presenta a sí mismo.

- Plantea una pretensión de validez subjetiva.

\section{Desarrollo. Ejemplificación del triple análisis. Estudio de caso de la imagen africana en El Mundo y El País \\ 3.1. El Mundo, camino a la asepsia}

En las noticias seleccionadas de $E l$ Mundo el abanico temático bajo el que aparece África es más amplio que en El País. Sin embargo, lo que podría apuntar a una imagen más poliédrica de un vasto continente acaba siendo tan sólo una falsa ilusión. Los variopintos contextos en los que se presenta forman un cajón desastre de unidades informativas que poco tienen que ver con África. 
La irrelevancia de África toma cuerpo a cada paso que se da con un relato distante. Y no es la distancia necesaria para ganar imparcialidad o perspectiva sobre lo que está ocurriendo en el mayor foco informativo, la crisis de Malí, sino que es el resultado del desinterés. Este conflicto armado entre los militares golpistas y las diferentes facciones de los tuaregs rebeldes es para El Mundo una mera "asonada militar y popular", de connotaciones negativas, típica del continente africano:

"Los golpistas de Malí prometen juzgar al presidente derrocado" (03-04-2012).

"Los rebeldes tuaregs ganan terreno en Malí y entran en la estratégica ciudad de Gao" (31-03-2012).

"Los países vecinos de Malí declaran un embargo contra la Junta Militar y enviarán tropas" (02-04-2012).

África es, en definitiva, un lugar alejado de la realidad española, fuera de los centros de poder mundiales. Los pocos recursos que destina El Mundo a Malí son proporcionales a la escasa importancia que le concede, con lo que los periodistas no pueden formarse una opinión sólida y el rotativo no alcanza una postura definida. Éstas son las causas de que no se tome partido en un conflicto tan relevante, para el que no se ha desplazado apenas ningún corresponsal o enviado especial que siga en primera persona los acontecimientos. Así las cosas, el relato se enfunda en una asepsia informativa de un marcado carácter descriptivo, como las noticias que se limitan a reproducir las declaraciones del capitán Amadou Haya Sanogo que aparecen en la Agence France-Presse (AFP):

"El jefe de la Junta Militar de Malí restablece la Constitución" (02-04-2012).

"Los países vecinos de Malí declaran un embargo contra la Junta Militar y enviarán tropas" (02-04-2012).

Que El Mundo no logre construir su propia interpretación de la crisis de Malí también responde a la arquitectura del relato. Como no se ha desplazado a periodistas a la zona, el diario está obligado a entrar en una cadena rígida de producción de la información que le deja poco margen de maniobra para aportar valor añadido con noticias menos oficialistas. Son la agencia Efe, en primera instancia, Reuters y France-Presse en segundo término, las que recogen la información sobre el terreno a través de ruedas de prensa y comunicados oficiales de la junta militar golpista, que es quien ahora ostenta el poder político y puede articular su propio discurso. Al diario no le queda otra que informar del conflicto desde el género más económico y convencional, la noticia, porque no puede saltarse los engranajes de una comunicación prefabricada por los actores institucionales. El Mundo reduce, así, el número de actores del relato y la complejidad de los acontecimientos.

Pese a que su imagen negativa sobrevuela a lo largo de, prácticamente, todas las noticias, las estrategias textuales que emplean los periodistas para trasladar sus preconcepciones a la sociedad no suelen ser evidentes, más bien son sutiles. La voluntad del periodista de no hacer demasiado explícito lo que es más bien latente en su representación mental de África se manifiesta en niveles más profundos y locales del texto y en su relación con el lector. Pero también en lo no dicho. 
En todo momento, el diario se limita a exponer el estado de cosas desde un papel constatativo, donde la fuerza de los hechos se impone como una verdad objetiva. La pretensión de validez de las informaciones queda así del lado de la agencia y el diario no hace más que ofrecer un soporte en el que trasladar el trabajo de selección y jerarquización previas a su público lector.

\subsubsection{La ciencia en El Mundo}

La segunda temática que domina el panorama africano en $E l$ Mundo es la científica. El continente es terreno abonado para los descubrimientos de la arqueología. Un total de tres noticias de las 20 seleccionadas hablan sobre el pasado prehistórico de países que despiertan la curiosidad de los investigadores:

"Los restos de la hoguera más antigua" (03-04-2012)

“Águila Roja' premiada en el World Media Festival de Hamburgo 2012"-(29-03-2012) (dentro de la noticia se pasa revista a un documental español sobre Africa, premiado en este festival)

"El homínido 'torpe' de hace 3,4 millones de años” (29-03-2012)

Este es el lugar de un relato documental que sigue con la tradicional mirada a los enigmas de un continente que no sólo es una fuente inagotable de fauna y flora para los países occidentales, sino que también es el lugar del origen de los seres humanos.

Desde la vertiente periodística, este tipo de noticias se apartan de la imagen negativa de África que reina en prácticamente toda la cobertura informativa. Para comenzar porque los descubrimientos científicos y los documentales reseñados se acompañan de una notable contextualización, con la aparición de una pluralidad de fuentes expertas en los temas abordados, lo que no sucede en el resto de unidades informativas. En estas noticias, además, se transmiten "valores humanos que contribuyen a la construcción de la comunidad y a la promoción del hombre" y se "desarrollan labores de sensibilidad cultural de los públicos" (Blanco, 2008) al considerar a África cuna de la evolución humana.

Estos actos de habla constatativos conforman un modo de comunicación cognitivo en el que el periodista hace referencia a un mundo objetivo de descubrimientos científicos. No entran en juego los valores de un mundo social consensuado tácitamente entre periodistas y lectores, por lo que la función de la comunicación no deja de ser la transmisión de conocimiento. La noticia no se inscribe, por tanto, en un proceso de coordinación social (Habermas, 1999a), porque la finalidad última no estriba en la persuasión del lector para que tome una postura o inicie una acción. En los hechos narrados hay una conexión interna entre el significado y la validez, con pretensiones de validez que residen en verdades científicas. El centro de gravedad temático, más concretamente, está en los propios avances de la paleontología.

\subsubsection{La salud en África, a debate}

En tercer lugar por número de apariciones se encuentran las dos noticias relacionadas con la salud en África.

"Oftalmólogos en peligro de extinción" (02-04-2012).

"El tratamiento preventivo de la malaria es eficaz fuera de África" (29-03-2012). 
Conforman un tipo de noticias de una mayor calidad informativa y mantienen ciertos paralelismos técnicos con la sección arqueológica. Son informaciones más exhaustivas y panorámicas que las habituales y en las que se valoran más los aspectos negativos que los positivos. Periodistas de El Mundo firman desde Madrid relatos interpretativos en los que una vez más se han puesto medios para no depender de las agencias de noticias, por lo que se cita la opinión de los expertos, revistas científicas de referencia e investigadores que aportan valor añadido a la información. Sin embargo, África vuelve a ocupar una posición colateral en noticias que repasan los resultados de estudios internacionales sobre la carencia de oftalmólogos en el mundo y los tratamientos preventivos de la malaria practicados fuera del continente africano. Pese a la variedad de fuentes que intervienen en la narración se publican en forma de noticias y no como reportajes u otro tipo de artículos. Bien es verdad que profundidad no falta a textos en los que también se despliega cierta corrección en un lenguaje que de forma directa no arremete contra la imagen de África.

Desde la óptica de la Pragmática Formal las noticias de la sección de salud son actos comunicativos orientados hacia el futuro, porque siempre alertan de situaciones que se agravarán con el paso del tiempo. Por las dimensiones del dramatismo humano son textos regulativos que buscan la implicación del lector con apelaciones a un mundo social de valores compartidos. Esta trama sociocultural toma asiento en la experiencia histórica de una sociedad del bienestar que ha conseguido la gratuidad y universalidad de un sistema de salud público forjado con los años en España. La apelación al lector es un elemento importante en la reactivación del papel que juega El Mundo en el espacio público.

\subsection{El País olvida al lector}

Pese a que el continente africano se presenta desde menos ángulos en El País, el tratamiento es más ecuánime o ajustado a la realidad, con una mayor pluralidad de fuentes consultadas. En la temática hegemónica, la crisis militar de Malí, el relato es más complejo y multivectorial porque participa un mayor número de actores, escenarios y versiones del acontecimiento. En esencia, el diálogo de voces de los actores es más amplio.

El País cubre el conflicto maliense en dos escenarios: en el país de origen, Malí, y en los ambientes diplomáticos de la sede de la ONU en Nueva York. La primera de las localizaciones empieza a estar cubierta por una periodista desplazada a la zona, Fátima Valcárcel, de manera que el tratamiento mediático va a mejorar porque en algunos casos se va a hacer sobre el terreno una gestión más estudiada de las fuentes de información:

"Los tuaregs toman por primera vez una capital de región" (31-03-2012);

"Los independentistas tuareg toman las grandes ciudades del norte" (01-04-2012).

La noticia es en esta primera parte el género más habitual para explicar el avance tuareg tras el golpe de estado en Malí. En general no hay una firme voluntad de estrechar lazos con el lector explorando una ideología en común. No se buscan abiertamente complicidades sobre la base de normas sociales compartidas. Como no se 
intenta comprometer de forma expresa la respuesta del lector, es probable que la noticia no llame la atención y que el consumo del producto mediático no desencadene opiniones, actitudes y acciones con la misma intensidad. No hay, por tanto, una conexión interna entre la recepción de la noticia y la acción (respuesta del lector). Son textos constatativos en los que el lenguaje expone un estado de cosas en un modo de comunicación cognitivo, que apenas guarda relación con el mundo social de la cultura española en la que se inscriben periodistas y lectores.

Y sin embargo, El País está más interesado en acentuar la autoría y la presencia de los periodistas en la narración. Esto significa que la vertiente subjetiva de los profesionales de la comunicación, pero también la de los personajes africanos de organismos internacionales, son reseñables en la cobertura de Malí. Por tanto desde la pragmática formal se evidencian más elementoues expresivos. Es el caso de la entrevista al jefe de la unidad africana de la UNESCO, Lazare Eloundou:

"Hay que salvar el patrimonio de Tombuctú" (03-04-2012)

El análisis de la semántica global de la noticia revela la prevalencia de los tuaregs en la estructura gramatical, en prácticamente la mitad de los titulares. El diario ha acercado posiciones a los colectivos tuaregs y, en ciertos momentos, los ha integrado como fuente de información y protagonistas del relato. Su posición de sujetos de la oración en la máxima expresión de la noticia, el titular, les reserva una cuota especial de protagonismo en el cuerpo del texto. No obstante, su presencia en los titulares recibe un tratamiento desigual. Porque en este espacio sólo se les caracteriza por las acciones que emprenden en la conquista de las principales ciudades del norte y nunca por lo que dicen:

"Los independentistas tuareg toman las grandes ciudades del norte" (01-04-2012)

Es como si la palabra quedara reservada a otros actores de este relato secuenciado, como Francia y los que ocupan cargos de relevancia en los organismos internacionales, como Lazare Eloundou en la UNESCO:

"Francia reclama en la ONU la máxima dureza contra los golpistas de Malî" (03-042012).

"Hay que salvar el patrimonio de Tombuctú" (03-04-2012)

Pero los tuaregs también son objeto de un lenguaje ambiguo que tan pronto reconoce la legitimidad de sus reivindicaciones, como se apunta a la hipótesis de una peligrosa sinergia entre los rebeldes nómadas y los yihadistas islámicos. Y es que la siniestra sombra de Al Qaeda siempre planea en las noticias.

"Los independentistas tuareg toman las grandes ciudades del norte de Malí" (01-042012)

"Malí sí importa" (29-03-2012)

\subsubsection{La inmigración irregular}

Un informe presentado por la senadora verde holandesa, Tineke Strip, al Consejo de Europa demuestra que la OTAN desoyó las llamadas de socorro de unos náufragos subsaharianos que el año pasado huían de la guerra contra Gadafi. El País sigue la 
pista de uno de los pocos supervivientes del naufragio que llega a Holanda a través de una larga travesía por diferentes países. El rotativo denuncia, primero, a través de la traducción de una noticia de The Guardian, la irresponsabilidad de los países de la OTAN que no prestaron ayuda a las personas que navegaban en una precaria embarcación. Además esa zona del Mediterráneo estaba repleta de todo tipo de barcos de guerra y aviones.

"Los responsables de la tragedia" (29-03-2012)

No hay ambages en la postura del periódico en una segunda noticia cuando se critica la intención del Gobierno holandés de expulsar al superviviente del naufragio, el ciudadano etíope Abu Kurke Kebato. O menos aún en un tercer movimiento con la publicación de un editorial en el que el diario muestra su postura ya de forma más abierta y explícita en este caso, en el que se lesionan derechos humanos fundamentales de asilo político.

"Holanda ordena detener y expulsar a uno de los náufragos que ignoró la OTAN" (3003-2012)

"La obligación de rescatar" (editorial, 01-04-2012)

El País publica artículos con un fuerte componente opinativo, basados en el informe de Tineke Strip. En los criterios de la calidad periodística son informaciones que profundizan en la realidad narrada, desde los antecedentes del bote con 72 subsaharianos a la deriva, a la descripción de la historia personal de Abu Kurke Kebato en Holanda. También en las distintas piezas informativas se transmiten valores humanos que contribuyen a la construcción de la comunidad y se desarrollan labores de sensibilidad moral del público lector. Sin embargo la capacidad de reflejar en sus páginas diferentes puntos de vista sobre un mismo asunto, como en el conflicto de Malí, no acaba de darse aquí en forma de un diálogo abierto y reflexivo en el que se dejen escuchar voces contrapuestas. Aunque es fundamental dejar bien claro quién es la víctima y quién el culpable, sí hay motivos suficientes para sostener esta posición, también lo es generar un discurso plural. Y El País únicamente recoge el informe de Strip, las declaraciones del abogado del etíope Abu Kurke Kebato, Marq Wijngaarden, y Amnistia Internacional. Todos ellos coinciden en que las autoridades de la OTAN obviaron los gritos y comunicaciones de auxilio y que el Gobierno holandés se equivoca con la expulsión precipitada del náufrago, una decisión que la cabecera atribuye al influjo de la extrema derecha en los Países Bajos.

Precisamente las dimensiones de la tragedia con 73 personas subsaharianas a bordo de un bote, en el que fallecerán la mayoría de sus tripulantes, y la crueldad con la que un Gobierno europeo expulsa de su espacio a uno de sus supervivientes, quien además ha realizado un duro periplo por diferentes países, obligan a El País a tomar cartas en el asunto. Por tanto elabora textos regulativos en los que se intenta acortar distancias y ganar complicidades entre el periodista, el lector y la comunidad internacional. Primero es una llamada a esclarecer lo ocurrido con el bote de subsaharianos a la deriva, invocando la obligación de proteger tanto a las víctimas de un conflicto armado, como a los que intentan escapar del horror de la guerra. Un trasfondo de valores socialmente 
aceptado en relaciones interpersonales (Habermas, 1999a: 415, 416) está detrás de la noticia a través de una indignación que se muestra entre líneas, por medio de frases cortas, contundentes: "No lo logró", "No fueron rescatados". También se contextualizan los diferentes episodios de una aventura desgraciada: "La travesía de Kurke, etíope de 23 años que dejó su hogar para evitar la violencia, ha vuelto a torcerse", "Como en Libia, la corriente devuelve a Kurke en contra de su voluntad". Hay una interna relación entre lo dicho y un pacto consensuado, tácito, que conecta al periodista con el lector en un marco común de interpretación que se nutre de la cultura y se pone en movimiento gracias a la socialización.

"Holanda ordena detener y expulsar a uno de los náufragos que ignoró la OTAN" (3003-2012)

Cuando se analiza cómo se desarrolla el significado a escala local del texto lo primero que destaca es la victimización de los náufragos subsaharianos. En todo momento, también hay que decirlo, el diario sale en defensa de los náufragos y apoya la versión de los hechos de la senadora verde holandesa. Se rompe, a su vez, con el anonimato en el que se destierra a los africanos en los medios, inscribiendo al etíope Abu Kurke Kebato en un proceso de personalización sin precedentes. Además de citarlo con nombre, apellidos, edad y nacionalidad, se explican las razones por las que deja su hogar, la violencia. De este modo, además, el diario se aparta del estereotipo del inmigrante africano que sólo viaja por necesidad económica. Al mismo tiempo se explica la travesía y su empeño por vivir. Sin embargo, el discurso informativo concede estas identidades individuales en contadas ocasiones, en las que los africanos son víctimas de tragedias de diferente naturaleza.

\subsubsection{La enfermedad y el hambre}

Hay dos reportajes que a pesar de no pertenecer a ninguna de los asuntos más reiterados en esta muestra vale la pena reseñarlos por su densidad semántica. Tratan sobre aspectos muy sensibles, todas ellos relacionados con la enfermedad y el hambre, todos ellos vinculados a la mortalidad infantil. Además, despiertan la mayor reacción entre los navegantes de la red de todas las noticias analizadas. Probablemente se debe a que estos reportajes ponen el acento en la vertiente humana de los personajes, con relatos que sitúan el centro de gravedad temático en los mismos actores.

El primero se ocupa de una de las enfermedades más desconocidas que azota a África, una epidemia que se ensaña con los más vulnerables, los niños y niñas. Despierta una descomunal respuesta de los lectores en las redes sociales.

"El síndrome que solo mata niños" (25-03-2012)

Una entrevista con el médico y misionero norteamericano Warren Cooper sirve para introducir al lector en el conocimiento de casos concretos de síndrome del cabeceo, que desde hace años está diezmando a la población infantil en zonas de África oriental, como Sudán del sur, norte de Uganda y sur de Tanzania. La experiencia de Cooper se pone al servicio del reportaje para situar los misteriosos orígenes de la rara enfermedad. La mortalidad infantil que provoca la epidemia es un argumento impor- 
tante para que el periodista se involucre de manera directa en el relato e invoque la presencia del lector digital. $\mathrm{Y}$ es que hay pocos temas que movilicen tanto a periodistas $\mathrm{y}$ a lectores en torno a una noticia.

El segundo reportaje avisa de la grave crisis alimentaria que puede afectar a Chad y también tuvo un eco importante en las redes sociales. Como en el anterior reportaje, no existe ningún grado de dependencia con las agencias de noticias y los organismos internacionales e institucionales, porque lo que importa es el testimonio en primera persona de la periodista.

"La vida al borde del hambre" (24-3-2012)

En el nivel superior y más general de la semántica, la vida es el sujeto gramatical del titular, con lo que ya se adelanta al lector que el vector humano va a centrar el interés de la pieza informativa. La malnutrición se está cebando con la población de Chad, pero muchas familias no acaban de identificar los síntomas y la combaten con métodos de curación tradicionales. Al drama de la desinformación, se suma el de unos 90.000 chadianos que regresan de Libia y que se encuentran un país sumido en la precariedad. El significado local que se despliega en las palabras, frases y en el estilo de la prosa periodística, mantiene importantes puntos de conexión entre los dos reportajes. En ambos se produce un proceso de individualización de los personajes, que son el eje del discurso y focalizan la mirada de los periodistas. Padecen situaciones inhumanas y aportan su testimonio individual a dramas humanos que a menudo se cuentan desde una perspectiva macrosocial.

No obstante, en paralelo a la aparición de la subjetividad de los actores, el reportaje trae imágenes recalcitrantes de lo africano. En este género, el periodista baja la guardia de la autocensura para dar rienda suelta a las representaciones más libres y espontáneas de lo africano, con lo que muestra más abiertamente sus definiciones de África. Al abandonar los convencionalismos formales, las normas de estilo más estrictas de la noticia, se abre paso a las licencias más subjetivas y humanas del profesional, donde cuenta la experiencia personal. Es, entonces, mucho más fácil que entren en juego los lugares comunes y las visiones más tradicionalmente occidentales de la África más atávica. Al tiempo que el reportaje sensibiliza y humaniza las cifras de las tragedias, porque transmite valores humanos, deja al descubierto el mundo subjetivo (o mundo de vida) del profesional de la comunicación. Y es aquí dónde en estos textos expresivos se cuelan prejuicios e imágenes estereotipadas porque, de alguna manera, se rompe con la "objetividad o imparcialidad" de la noticia. En este contexto, hay una dialéctica que se repite en el periódico: el paisaje tribal y precientífico de África choca con la ciencia de Occidente. Curanderos tribales, las teorías más peregrinas de los consejos de ancianos de las aldeas, y cuestiones culturales de África, que colisionan con el ejercicio médico. Algunos ejemplos del reportaje "La vida al borde del hambre" (24-3-2012):

"Nadie en las aldeas tiene explicación para lo que les pasa a los niños. Los más viejos han contado a los investigadores las teorías más peregrinas. Los dinka, la tribu mayoritaria en Sudán del Sur, culpaban del mal a la costumbre de algunas tribus de comer carne de mono. La superstición también sembró dudas sobre las vacunas occidentales, las armas químicas utilizadas durante los conflictos, los matrimonios entre los miembros de algunas 
tribus con desplazados de la guerra, el ataque de unas moscas y otras causas sobrenaturales, según relataron en 2011 a un grupo de expertos sudaneses en Witto Payam, al oeste de Sudán del Sur. (Investigation into the Nodding syndrome in Witto Payam, Western Equatoria State, 2010, Southern Sudan Medical Journal)"

"El doctor Cooper, que intentó hacer una biopsia cerebral a un niño que había fallecido... No conseguí que me dejaran, probablemente por razones culturales".

"Tampoco funcionó que al pequeño Koubra, de tres meses, le quemaran con un hierro candente y una punta de algodón en el pecho cuando empezó a tener problemas para respirar. Muchos otros padres en las zonas remotas de Chad acuden a los remedios tradicionales para sanar algo que no siempre son capaces de identificar".

"Un mercado medieval debía ser muy parecido al de Mao, donde las moscas y los burros de carga trasiegan en las callejuelas abarrotadas de gente y de puestos de tomates secos, zanahorias, cereales y alguno de jabón y cosméticos chinos".

\section{Conclusiones}

Aportamos en este artículo una propuesta metodológica que potencia la interacción entre investigador y noticia. Se trata de no reducir el análisis, exclusivamente, a un material lingüístico. La perspectiva que se plantea en este modelo de análisis se acerca al discurso de una manera más abierta. Desde un análisis estrictamente periodístico se analiza la noticia como un producto mediático que responde a una serie de rutinas y a determinados criterios de calidad; en cambio desde un análisis semántico y desde la pragmática formal enmarcamos la situación comunicativa que mantienen periodistas y lectores y se contextualiza la noticias en otros marcos en los que actúa y puede ser comprendida.

Así vemos que la representación mediática de África en las versiones digitales de los dos diarios analizados viene condicionada por un paso previo. El continente africano sigue confinado en un imaginario individual y colectivo que le reserva un lugar semántico y un espacio residual en el marco conceptual del periodista. La construcción negativa de la imagen africana en los medios es antes simbólica que textual, antes social que mediática. Se puede observar en aspectos latentes del texto, en todo lo obviado por el periodista así como en la caracterización de los diferentes protagonistas. Hemos ejemplificado que cuando los protagonistas son africanos se definen por lo que hacen y no por lo que dicen, a diferencia de lo que pasa con los países desarrollados.

Siguiendo un análisis periodístico, la falta de recursos empleados para explicar África y la excesiva dependencia de las fuentes secundarias confinan a estos diarios a la noticia como género más económico. El reportaje y la crónica, por contra, reclaman más recursos y una cobertura más integral. Si en El Mundo son las agencias las que imponen el filtro y la arquitectura de la narración, en El País son más bien los medios públicos de Malí. Las convenciones estilísticas, la aparente corrección del lenguaje y la rígida estructura narrativa de la noticia, ayudan a ocultar las imágenes más recalcitrantes de lo africano. Además, la asepsia es la actitud que imposibilita la selección de otros temas noticiables así como de describir un buen plano de situación de los hechos. Se interpone una distancia insalvable entre el profesional y la narración de la realidad, una distancia que acaba dominando la propia mirada periodística. Con su 
actitud distante, ambas cabeceras no sólo renuncian a construir con su propia voz un discurso trabajado, sino también al rol que juegan como especialistas en el relato en una sociedad avanzada. La ley del mínimo esfuerzo explica, además, que se den por buenas las interpretaciones de las agencias y de los medios públicos de Malí, siempre que coincidan con los lugares comunes de los periodistas. Y es que la indefinición estructural en sus posicionamientos trae como consecuencia contradicciones, ambigüedades en el tratamiento de los actores y voces silenciadas. Al final, el conflicto de Malí, escapa al marco de interpretación sociocultural de los dos diarios analizados.

En términos de pragmática formal habermasiana los periodistas no han sido capaces de interpelar al lector, de implicarlo en el relato ni de poner en común el entramado de valores que les unen a través de las noticias. En la mayoría de los casos sólo es posible exponer un estado de cosas de una realidad lejana e intrascendente. Es entonces cuando la fuerza de los hechos (narrados por otros agentes) se impone como una verdad objetiva. Además, la sobriedad del lenguaje objetivista aporta el efecto de una falsa verosimilitud que cubre el trasfondo semántico de las informaciones.

Es la propia desidia informativa la que explica, en el fondo, que las noticias estén planteadas como textos constatativos en el discurso informativo. El conflicto de Malí y los descubrimientos científicos están escritos desde esta perspectiva. Son marginales los textos regulativos que señalan un cambio de actitud en el intento de llamar la atención del lector. El Mundo despierta de su indiferencia con los temas relacionados con la salud y la pobreza, desde los que tradicionalmente se ha visto a África; mientras que El País se sacude su pasividad informativa cuando toma partido por los subsaharianos que escapan del desastre libio en el epígrafe "La inmigración irregular". Los rotativos establecen formas de vinculación con el lector sólo en determinados dramas humanos, que encajan bien con la fatalidad que se atribuye al continente negro desde siempre.

Sin embargo en los reportajes de El País sobre el hambre y la enfermedad se rompe con toda regla del discurso informativo. En las noticias el estilo y la "objetividad", parcialmente construida, cierran el paso a los prejuicios más abiertamente conservadores del mundo subjetivo del periodista y de la esfera sociocultural en la que vive. No obstante, los textos expresivos del reportaje abren la puerta a la mirada más personal del redactor y a los recursos literarios. En el reportaje hay menos mecanismos para retener o disimular los prejuicios y los lugares comunes, que quedan al descubierto. Las imágenes más descarnadas de África se encuentran en unidades informativas que por su carga dramática obtienen un gran eco virtual.

\section{Referencias bibliográficas}

ALTARRIBA, Miquel et al. (2008): Usos i actituds dels immigrants davant dels mitjans de comunicació. Barcelona, Consell de l'Audiovisual de Catalunya (CAC).

ALONSO, Luis Enrique; CALLEJO, Javier (1999): "El análisis del discurso: del postmodernismo a las razones prácticas". Reis: http://www.reis.cis.es/REIS/PDF /REIS_088_04.pdf [Consulta: 20 de diciembre de 2013].

AUSTIN, John L. (1982): Cómo hacer cosas con palabras: Palabras y acciones. Barcelona, Paidós. 
AYUSTE, Ana; MEDINA, Alfons; PAYÀ SÁNCHEZ, Montserrat et al. (2009): "El significat del projecte migratori: les dones parlen de la seva experiencia". Temps d'educació, $\mathrm{n}^{\circ}$ 37. Barcelona, Universitat de Barcelona, pp. 149-168.

BAÑÓN HERNÁNDEZ, Antonio (2006): "Mali y los inmigrantes malienses. Notas sobre la representación discursiva en el diario EL PAIIS", en LARIO, Manuel (coord.): Medios de comunicación e inmigración. Murcia, Convivir sin racismo, pp. 171-200.

BAÑÓN HERNÁNDEZ, Antonio (2007): "El discurso periodístico a propósito del viaje de los inmigrantes pobres", en ZAPATA-BARRERO, Ricard y DIJK, Teun A. van (eds.): Discursos sobre la inmigración en España: los medios de comunicación, los Parlamentos y las Administraciones. Barcelona, CIDOB (Centro de Investigación de Relaciones Internacionales y Desarrollo), pp. 45-67.

BAÑÓN HERNÁNDEZ, Antonio (2010): “'No dejes que la realidad...': Representación discursiva de las personas inmigradas en el caso Roquetas 2008", en MARTÍNEZ, María (ed.): Migraciones, discursos e ideologías en una sociedad globalizada. Claves para su mejor comprensión. Alicante, Instituto de Cultura Juan Gil Albert, pp. 43-56.

BAUBÖCK, Rainer (2004): “Cómo transforma la inmigración a la ciudadanía: perspectivas internacionales, multinacionales y transnacionales", en AUBARELL, Gemma y ZAPATA, Ricard: Inmigración y procesos de cambio. Europa y el Mediterráneo en el contexto global. Barcelona, Icaria, pp. 177-214.

BERNÁRDEZ, Asunción (2007): Mujeres inmigrantes en España. Representaciones en la información y percepción social. Madrid, Fragua.

BLANCO, $\mathrm{M}^{\mathrm{a}}$ del Mar (2008): Modelos de análisis para el estudio crítico de la prensa. Madrid, Ediciones Internacionales Universitarias.

BUSQUET, Jordi y MEDINA, Alfons (2014): Invitación a la sociología de la comunicación. Barcelona, Editorial UOC.

CANOSA, Francesc et al. (2009): "La visibilitat i la invisibilitat dels immigrants en els mitjans de comunicació (premsa, ràdio, televisió i la xarxa)", en MEDINA, Alfons; ROM, Josep; y CANOSA, Francesc (eds.): Trípodos, Extra, Vol. 1. Barcelona, Facultad de Comunicación Blanquerna, pp. 517-526.

CASTEL, Antoni y SENDÍN, José Carlos (2009): Imaginar África. Los estereotipos occidentales sobre África y los africanos. Madrid, Los Libros de la Catarata.

CONCEPCIÓN, Luis; RODRIGO, Miquel; MEDINA, Pilar (2008): "Niveles semánticos de las representaciones sociales de la inmigración subsahariana. Los sucesos de Ceuta y Melilla según $A B C^{\prime \prime}$. Estudios sobre el Mensaje Periodístico, vol. 14. Madrid, Servicio de Publicaciones de la Universidad Complutense, pp. 129-148.

CONCEPCIÓN, Luis y MEDINA, Alfons (2011): "Claves teóricas para una nueva visión de la recepción mediática desde la experiencia migratoria". Correspondencias \& análisis, ${ }^{\circ} 1$. Lima (Perú), Universidad San Martín de Porres, pp. 369-384. 
COGO, Denise; ELHAJJI, Mohammed; y HUERTAS, Amparo (eds., 2012): Diásporas, migraciones, tecnologías de la comunicación e identidades. Bellaterra, Institut de la Comunicació (Universitat Autònoma de Barcelona).

CHAVERO, Haydeé et al. (2005): "Los hábitos del consumo televisivo de una comunidad extranjera: el caso de estudiantes latinoamericanos en Barcelona". Revista de estudios de comunicación Zer, $\mathrm{n}^{\mathrm{o}}$ 19. Bilbao, Universidad del País Vasco, pp. 191-204.

EL-MADKOURI, Mohamed (2004): "España y el mundo árabe: imagen e imaginario". Tonos digital, revista electrónica de estudios filológicos, $\mathrm{n}^{\circ} 7$. Murcia, Servicio de Publicaciones de la Universidad de Murcia.

EL-MADKOURI, Mohamed (2006): "El Otro entre Nosotros: el musulmán en la prensa", en LARIO, Manuel (coord.): Medios de comunicación e inmigración. Murcia, Convivir sin racismo, pp. 96-122.

FREIXA, Omer (2012): "El tratamiento por parte de los medios del continente africano", en el portal Red Safe World: http://www.redsafeworld.net/news/el-tratamiento-por-parte-de-los-medios-del-continente-africano-omer-freixa-/ [Consulta: 24 de mayo de 2014].

FREIXA, Omer (2013): “África, a ojos muy simples”, en el blog de El País: http://blogs.elpais.com/africa-no-es-un-pais/2013/12/africa-guerras-estereotiposmandela.html [Consulta: 14 de mayo de 2014].

HABERMAS, Jürgen (1994): Teoría de la acción comunicativa: complementos y estudios previos. Madrid, Cátedra.

HABERMAS, Jürgen (1999a): Teoría de la acción comunicativa, I. Racionalidad de la acción y racionalización social. Madrid, Santillana.

HABERMAS, Jürgen (1999b): Teoría de la acción comunicativa, II. Crítica a la razón funcionalista. Madrid, Santillana.

HABERMAS, Jürgen (2008): El discurso filosófico de la modernidad. Madrid, Katz Editores.

HEIDEGGER, Martin (1994): "La pregunta por la técnica", en Conferencias y artículos. Barcelona, Ediciones del Serbal, pp. 9-32.

HUSSERL, Edmund (1991): La crisis de las ciencias europeas y la fenomenología transcendental. Barcelona, Crítica.

IGARTUA, Juan José; MUÑIZ, Carlos; y CHENG, Lifen (2005): "La inmigración en la prensa española. Aportaciones empíricas y metodológicas desde la teoría del encuadre noticioso", en Revista Migraciones: http://www.upcomillas.es/pagnew/iem/04publicaciones/migraciones/documentos/17/estudio5.pdf [fecha de consulta: enero de 2014].

JENSEN, Klaus Bruhn y JANKOWSKI, Nicholas Warren (2003): Metodologías cualitativas de investigación en comunicación de masas. Barcelona, Bosch.

LEUNG, Linda (2008): Etnicidad virtual. Raza, resistencia y World Wide Web. Barcelona, Gedisa. 
MUÑOZ, Claudia (2014): "Jürgen Habermas y la teoría de los actos de habla": http://media.wix.com/ugd/6de50a_2431d5cfa4d776e6ef0a3cafa402642a.pdf?dn= lectura_modulo_etica_del_discurso.pdf [Fecha de consulta: marzo de 2014].

NERÍN, Gustau y LÓPEZ, Lola (1999): La imatge de l'África negra en la televisió. Barcelona, Centre d'Estudis Africans.

SEARLE, John (2001): Actos de habla. Madrid, Cátedra.

SENDÍN, José Carlos (coord., 2004): "África: entre la percepción externa y el proyecto emancipador". Cuadernos Bakeaz n ${ }^{\circ}$ 64. Bilbao, Bakeaz, pp. 1-16.

SENDÍN, José Carlos (2006): Problemas asociados a la construcción del africano en los medios de comunicación en España: análisis del tratamiento informativo de la crisis de Ruanda en televisión española. Tesis doctoral no publicada. Madrid, Universidad Rey Juan Carlos.

TAIBI, Mustapha y EL-MADKOURI, Mohamed (2006): "Estrategias discursivas en la representación del Otro árabe", en LARIO, Manuel (coord.): Medios de comunicación e inmigración. Murcia, Convivir sin racismo, pp. 125-144. 